\title{
Fostering professional development and improving the psychological health of nurses through the North American certification process in critical care
}

\author{
Geneviève Beaudoin ${ }^{1}$, Marie Alderson ${ }^{1}$, Lyne St-Louis ${ }^{2}$ \\ 1. Faculty of Nursing, University of Montreal, Montreal, Canada. 2. Jewish General Hospital of Montreal, University of \\ Montreal, Montreal, Canada.
}

Correspondence: Geneviève Beaudoin. Address: Faculty of Nursing, University of Montreal, 2375, chemin de la Côte-Ste-Catherine, Montreal, Qc, H3T 1A8, Montreal, Canada. Email: genevieve.beaudoin.1@umontreal.ca

Received: May 1, 2013

Accepted: July 15, 2013

Online Published: September 10, 2013

DOI : 10.5430/jnep.v4n1p177

URL: http://dx.doi.org/10.5430/jnep.v4n1p177

\begin{abstract}
Background: National certification in a nursing specialty is reported, in some articles, as a key approach to generate psychological and professional growth of nurses. Intensive care units generate, by their structure and the complexity of the clinical situations encountered, a high level of physical and psychological stress for nurses. These stressors affect job satisfaction, retention, and job attraction toward those intensive care units. One of the solutions proposed, in the literature, is continuous education to improve nurses' personal and professional development. Nurses gain the opportunity to enhance their autonomy and control over practice through certification, which can lead to empowerment.
\end{abstract}

Methodology: A critical review of the literature was conducted for a master's program to explore the impacts of the certification process on nurses as well as on patients and organizations. North-American manuscripts published from 2001 to 2013 were selected using Cumulative Index to Nursing and Allied Health Literature (CINAHL), Medline (PubMed), Proquest, PsychINFO, and EMBASE (Ovid) databases. University library catalogues and national associations' Internet resources were also consulted. Papers were classified by type of document and main subject. Overall, 105 articles were found and 45 excluded.

Principal Findings: Studies have shown that the certification process in a specific specialty such as critical care has been beneficial for nurses, patients, and organizations. It increases nurses’ professional satisfaction, autonomy, self-confidence, and empowerment. The certification process is also potentially linked to a decrease in morbidity and patient mortality. Finally, on an organizational level, the certification process is linked to an increase in recruitment and retention of nurses. However, most studies have used correlational and retrospective study designs, which might be considered biased. The literature review elicits the lack of research that can establish causal links between the variables and the quasi absence of quantitative benefits related to certification.

Conclusions: From the articles reviewed, it can be hypothesized that the certification process could potentially generate many benefits and represent a promising approach to enhancing empowerment for intensive care nurses. Organizations and patients can also benefit from knowledgeable, satisfied, and empowered health care professionals. In addition, there are potential benefits for the organizations if they provide the necessary support systems to promote and help nurses throughout the certification process. This can ultimately improve the psychological health of nurses. Researchers should seek evidence-based studies to support the information provided in the literature review. 


\section{Keys words}

Certification, Nursing, Empowerment, Psychological health

\section{I ntroduction}

In the current socio-economic context, intensive care settings are facing new challenges in terms of resources in addition to the existing challenges such as staff shortage and budgetary limitations ${ }^{[1-9]}$. In the literature, several authors have highlighted that the organizational and environmental characteristics of these units have an impact on the psychological and physical health of nurses ${ }^{[9-16]}$. These stressors result in high absenteeism and job dissatisfaction ${ }^{[8,17]}$. In addition, intensive care settings have difficulty in recruiting and retaining nurses ${ }^{[11]}$. A study done by Fitzpatrick, Campo, and Lavandero Graham ${ }^{[18]}$ revealed that among the 6,589 intensive care nurses in the United States involved in the study, 41\% of nurses intended to leave their jobs over the following twelve months. During the last decade, researchers have attempted to discover possible interventions to address these issues of retention and work satisfaction. One of the solutions identified by both Kuokkanen, Leino-Kilpi and Katajisto; and Leblanc and Sylvain ${ }^{[6,19]}$ is continuous education as a source of personal and professional development. Educational activities tailored to nurses' needs, and made available by the organization, promote acquisition of new knowledge, further professional autonomy, and provide a sense of control over nursing practice ${ }^{[20]}$.

Empowerment is the psychological term used in the literature to describe enhancement of professional autonomy and control over professional practice ${ }^{[20-23]}$. This form of professional development, to be defined in more depth in this article, has the potential to reduce stress and increase professional satisfaction ${ }^{[19,20,24,25]}$. More specifically, the certification process in a nursing specialty is emerging as a key approach to enhancing empowerment ${ }^{[6,18,26-29]}$. Furthermore, a link can be established between continuous education and the psychological health of nurses. Both managers and clinicians should consider the potential of the certification effects to justify the development of projects related to this professional activity. Consequently, the work environment of current and future professionals can be significantly improved.

This literature review aims, first, to report the benefits of the certification process at various levels for healthcare organizations, and second, identify the benefits of this process on the psychological health of nurses. In order to clearly explain the problematic of nurses' mental health and the certification process as a solution to improve it, the following sections of this article will describe the ICU work environment, the concepts of North American nursing certification, and empowerment. In this article, the term ICU refers to critical care units, which include adult and pediatric intensive care units, emergency department and perioperative units.

\section{Nursing work in intensive care units: Current status}

In intensive care settings, significant levels of stress and burnout, as well as a higher incidence of symptoms associated with Post Traumatic Stress Disorder (PTSD), have been reported among professionals working in these clinical settings in comparison to other care units ${ }^{[10,13,15,16,30,31]}$. The critical care environment is well-known for its fast pace ${ }^{[9,11,32]}$, the complexity of clinical situations encountered ${ }^{[9,11-13,32]}$, and the challenges health care professionals face when trying to establish a therapeutic relationship with a family in crisis ${ }^{[9,33]}$. The stressors nursing staffs have to cope with on a daily basis can explain high absenteeism rate and staff turnover ${ }^{[34]}$. Some nurses are able to adapt to critical care and are up to the challenges ${ }^{[11]}$. However, for other nurses, the adaptation is more difficult and can contribute to reducing their commitment and work satisfaction ${ }^{[11]}$. The stressful environment where nurses work is likely to affect the professionals as well as the patients, and therefore, the entire organization ${ }^{[35]}$. To prevent the negative consequences of stress, the authors recommend that nurses find, in their work, sources of personal and professional growth ${ }^{[6,36]}$. In addition, when resources to facilitate professional growth are available and accessible in the health care setting, positive feelings and attitudes emerge. Empowerment needs to be clearly defined in the context of organizational health in order to understand its implications on nurses and their psychological health. The following section aims to explain this concept. 


\section{Empowerment and its potential contribution to mental health of nurses}

According to Kuokkanen et al. ${ }^{[6]}$, empowerment can be defined as a perception of growth and personal development whose evolution is affected by the values\#and motivations of the individual. These authors have shown that a strong positive relationship exists among job satisfaction, commitment, level of professional activity and empowerment. Cho, Spence Laschinger and Wong ${ }^{[37]}$ also observed this correlation. As stated by these researchers, initiatives and programs that foster empowerment in an organization create a better quality of life at work, which reduces the level of burnout among professionals. Based on this study, a work environment that promotes workers' health can foster an increased level of commitment from the nurses. However, it is important to mention that the correlational study designs used to guide these researches may have introduced some bias. Furthermore, such studies do not allow the establishment of causal links. Therefore, the results obtained should be considered as an interpretation of the variables studied. The increased level of satisfaction of nurses might not be a direct result of empowerment. Other factors could have contributed to the nurses' satisfaction. However, researches lead by Kuokkanen et al. ${ }^{[6]}$ and Cho, Spence Laschinger and Wong ${ }^{[37]}$ also support the hypothesis that empowerment increases nurses' satisfaction.

Upenieks ${ }^{[38]}$ and Leblanc and Sylvain ${ }^{[19]}$ emphasize that in bringing a person to grow on a personal and professional level, autonomy increases, as well as factors inherent to the person, the relationships with others, and the organization. This reflects on the activities that would have the potential to contribute to developing and strengthening empowerment of nurses. According to the literature ${ }^{[9,18,39]}$, it seems that national certification is an interesting option.

\section{Certification process: A description}

Since 1984, the Canadian Association of Nurses allows nurses with a minimum of two years of clinical experience in a specialty to develop and demonstrate their knowledge in one of nineteen specialties offered ${ }^{[40]}$. Participants are invited to study in a specialty according to objectives provided by the association and pass a written exam after an average of eight months of study. Renewable every five years, this approach is an attestation of competence and quality that is valued by employers ${ }^{[41]}$. At the political level, the ex-President of the Order of Nurses of Quebec (ONQ), Gyslaine Desrosiers ${ }^{[2]}$, stated, in 2005, that the ONQ recognized that nurses must develop their knowledge and skills to face the growing complexity of clinical situations and new professional challenges. To meet these challenges, the OIIQ considers that the recognition of specialties is necessary. It seems that the certification process can help promote specialization ${ }^{[42]}$.

Studies have shown that the certification process is beneficial on various levels ${ }^{[20,31,42-44]}$. The following paragraphs describe how and which aspects of the certification process can be helpful to nurses. Although U.S. and Canadian certifycations are different, they share similarities in terms of processes, bringing the authors of this article to consider results of studies done in the United States, which are presented in the following section.

\section{Method of literature review}

This critical review of literature was undertaken during graduate studies and was part of a mandatory assignment. It was decided that a critical review, rather than a systematic review or a meta-analysis, would be more suitable due to time restrictions and academic expectations. The purpose was to explore, in the nursing discipline, the different aspects of certification. To search for relevant literature, databases CINAHL, Medline (PubMed), Proquest, PsychINFO and EMBASE (Ovid) were used. The Catalog Atrium of University of Montreal, which includes articles, books and institutional documentaries of this university, has been consulted to enrich this literature review. In order to complete this critical literature review, the websites of Statistics Canada, the International Committee of Nurses (ICN), the Association of Nurses (CNA), and the Ministry of Health and Social Services (MSSS) were also consulted. Finally, the research modules Web of Science and Google Scholar allowed access to documents that have not been identified by the databases named above. The keyword used, individually or as a combination, to search for the various sources were the following: "Nurses, Occupational Health and Mental Health, Critical Care or Intensive Care, stress, empowerment and certification 
(Credentialing).” The bibliographies of the articles retrieved were also consulted and other pertinent articles were found. A total of 105 articles were selected based on the following inclusion criteria: (1) writing language - French or English, (2) key words "certification", "nurse", "effect” or "impact" in the title or the abstract, and (3) available under electronic or paper version. To ensure an exhaustive exploration of the subject, a publication period between 2001 and 2013 was chosen. Exclusion criteria were: (1) writing language other than French or English, (2) geographical location other than Canada or United States, and (3) specialties other than critical care (emergency, intensive care, perioperative). Articles were to be North American in order to allow a comparison between the targeted nurses’ population. No quality review was done during this period due to time and context restrictions. This yielded a number of interesting articles published in the last decade. At the end of this research, 45 papers were excluded because they didn’t meet inclusion criteria.

Of the 60 remaining articles, six were statistical reports, twelve discussed stressors and psychological issues in critical care, eighteen explored the various effects of empowerment on mental health, seventeen focused on the impact of national certification in a nursing specialty on the person, the professional and the organization, and seven qualitative articles referred to some concepts of empowerment theoretical framework. Regarding the combination of the concepts of certifycation (empowerment and psychological health), no writing has gathered nor established a link among these three concepts up until now. It appears, therefore, that the topic addressed by this literature review is still underdeveloped.

\section{Theoretical framework}

The framework used to classify and analyze the literature is the theory of Kanter ${ }^{[45]}$, as revised and updated by Heather K. Spence Laschinger (Ph.D. in nursing sciences) ${ }^{[23]}$. According to Kanter ${ }^{[45]}$, the structure of the working environment and the perception to access formal and informal sources of power are directly correlated to attitudes and employees' behaviors in organizations. The environment must provide opportunities for growth, flexibility, and the opportunity to increase knowledge and develop clinical skills. Then, it must make available human and material resources, as well as information such as expertise and support in the form of mentoring or tutoring. Finally, for empowerment to be achieved, professionals must perceive that he or she has formal power to obtain a job offering flexibility, visibility, and creativity. In addition, the work environment must also offer informal power, which is the possibility to build relationships with peers and other members of the organization. As stated by Spence Laschinger, Finegan, Shamian and Wilk ${ }^{[46,47]}$, when structural elements are present and accessible, workers are able to develop psychological empowerment. The following figure illustrates the theory of Kanter ${ }^{[45]}$ according to Spence Laschinger's conceptualization ${ }^{[23]}$. It allows visualization of the relationship between the concepts.

Figure 1. Theoretical representation of the theory of Kanter ${ }^{[45]}$ by Spence Laschinger et al. ${ }^{[23]}$.

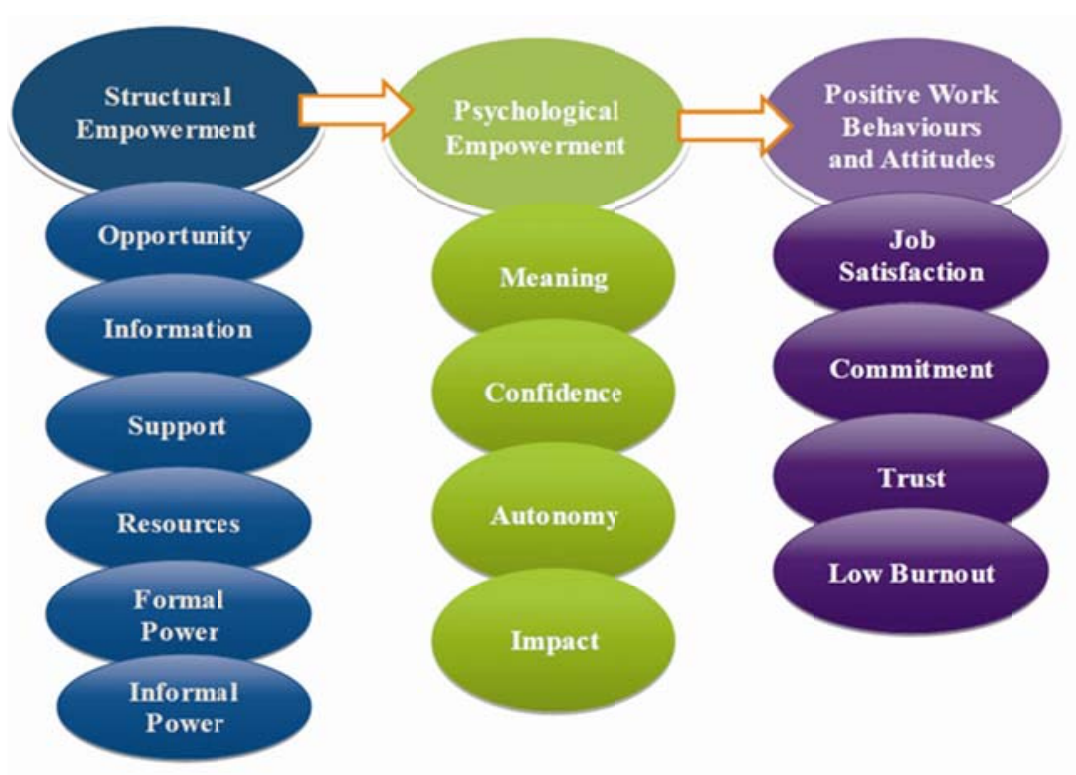


Spence Laschinger and colleagues ${ }^{[46]}$ demonstrated that the characteristics of an organization, as described above, favoring the emergence of feelings of autonomy, have an impact on work environment as well as on the organization, and enhance control over practice. According to their results, decreased burnout and increased confidence in leadership are also observed. Consequently, job satisfaction and commitment towards the organization are increased. Ultimately, the quality of care to patients is improved ${ }^{[46]}$. In other words, when the policies and interventions are put in place in a work environment focused on the professional development and support of the employees, psychological health, satisfaction, and employee growth can be enriched. In addition, the organization becomes more productive. The literature review looked at the associations between the concepts of empowerment and certification. The findings were classified according to the concepts described in Spence Laschinger's ${ }^{[23]}$ figure 1: organizational structure, psychological empowerment, and positive attitudes and behaviors at work (following certification process). The results of the literature analysis are presented below and highlight that nurses' mental health can be improved by the participation in a national certification program.

\section{The contribution of the certification process to psychological empowerment of nurses working in intensive care units}

\section{Certification as part of the organizational structure of empowerment}

In 2003, the American Association of Critical Care Nurses (AACN) ${ }^{[43]}$ highlighted, through a literature review presented as an editorial, that certification was a major source of personal growth and job satisfaction. Nedd ${ }^{[21]}$ and Spence Laschinger, Leiter, and Gilin Day ${ }^{[48]}$ found that, following quantitative descriptive correlational design studies, the presence of structures of empowerment positively influence job satisfaction and increase the desire of nurses to remain in the organization. More specifically, Wynd ${ }^{[49]}$ showed, through a quantitative study conducted using a correlational design with 1,850 nurses in Ohio, that the specialty certification was related to a higher level of professionalism. In addition, this study also proposed that attitudes of autonomy, confidence, and independence were particularly developed among certified nurses. Nurses said they were better prepared to intervene with critically ill patients. According to this researcher, the clinical care settings would benefit from supporting the certification process as it can increase their credibility, as well as facilitate attraction and retention of human resources ${ }^{[49]}$. However, the conclusions reported from those correlations should be considered as potentially right, but also influenced by other factors or circumstances. Certification could be beneficial for organizations in different ways, but studies could not prove causal links due to their non-experimental structures.

\section{The emergence of psychological empowerment through national certification}

Piazza, Donahue, Dykes, Griffin and Fitzpatrick ${ }^{[22]}$ underlined, through a quantitative comparative study design, that the perception of the empowerment of nurses certified in a specialty was significantly higher than those who did not complete this process of knowledge validation. This result was corroborated by a quantitative correlational study led by Fitzpatrick et al. ${ }^{[18]}$ with 6,589 American nurses working in intensive care. Samedy, Griffin, Capitulo and Fitzpatrick ${ }^{[50]}$ also obtained similar results in a quantitative descriptive study conducted with perinatal nurses. In all three studies, certified nurses who completed the certification process reported an increase in their formal and informal power, as well as, an easier access to information. These results are consistent with Laschinger's model ${ }^{[47]}$, which used Kanter's theory ${ }^{[45]}$. Krapohl, Manojlovich Redman and Zhang ${ }^{[51]}$ also confirmed, with their correlational descriptive study conducted among 450 American nurses, that there is a positive and significant link between the certification process and the perception of empowerment.

Meanwhile, Gaberson, Schroeter, Killen and Valentine ${ }^{[28]}$, found in a study conducted with 2,750 American Nurses certified in perioperative care (using a quantitative descriptive study design), that more than $90 \%$ of the participants reported personal and professional growth as well as a sense of accomplishment, an increase in specialized knowledge, and the achievement of higher practice standards following the certification process. Furthermore, they felt more professionally committed and better prepared to face clinical challenges, and experienced an enhancement of their profe- 
ssional credibility. This study was part of the first phase of a major research initiated by Byrne, Valentine and Carter ${ }^{[52]}$ investigating the value associated with the certification. In the second phase, Sechrist, Valentine and Berlin ${ }^{[53]}$ conducted a quantitative study to compare groups of nurses working in perioperative according to their professional title or certification status. The perception of value of certification tool (PVCT), developed by the Board of Certification in perioperative nursing (CBPN) in 2004, was mailed to the entire targeted population in the form of a survey. The average response rate was $55.5 \%$. The results obtained were very similar to those of Gaberson et al. ${ }^{[28]}$. However, Sechrist et al. ${ }^{[53]}$ were able to exclude the age and experience as influencing factors. Grief ${ }^{[54]}$ and Niebuhr and Biel ${ }^{[55]}$ were also able to identify, following a quantitative exploratory study designed with " 11,000 nurses representing 36 different nursing certification credentials" ${ }^{[54]}$, that the same intrinsic benefits were associated with the certification process. These authors interpreted the results from a national survey conducted in 2004 by the American Board of Nursing Specialties (ABNS). Increased autonomy, personal satisfaction, and self-confidence among nurses of all specialties are the factors that largely emerged from this study. The authors also discerned, on an extrinsic level, a perception of a form of recognition by the employer and the patients, as well as an increase in market value of the nurse. These intrinsic and extrinsic benefits have also been reported by Briggs et al. ${ }^{[42]}$ in an editorial discussing the results of a survey looking at the certification process from the perspective of managers of critical care units, members of the NCAA, in 2004. Thus, the literature has revealed the potentially significant contribution of the certification process in terms of the personal and professional development of nurses.

\section{The benefits of empowerment following the national certification process}

For the organization Miller and Boyle ${ }^{[56]}$ mentioned, in an editorial describing the results of surveys and databases of U.S. agencies, that the contribution of nurses certified in a specialty goes well beyond the promotional aspect for the hospital. These professionals are a source of support and reference in their clinical settings. They help achieve high quality standards and promote the certification of other colleagues. Moreover, Fitzpatrick et al. ${ }^{[18]}$ have demonstrated that the desire of nurses to leave their position was significantly lower among certified nurses. Additionally, the observation was

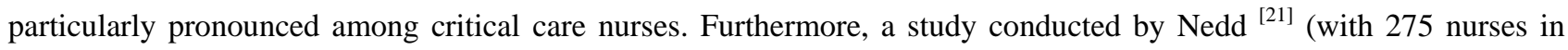
Florida) revealed that the presence of empowerment factors in clinical settings was associated with an increased intention of nurses to remain in the organization. More specifically, organizational structures aiming to support nursing staffs have been proven to be more influential in the retention of nurses than personal factors among these professionals. These results are consistent with the theory of Kanter ${ }^{[45]}$, which emphasizes that a working environment focusing on supporting and developing professionals has a more significant influence on job satisfaction than personality traits of professionals.

For the patient Krapohl et al. ${ }^{[51]}$ attempted to determine, through a non-experimental descriptive correlational study design, the impact of the certification process on patients' outcomes. The results, however, did not determine a significant relationship between the proportion of certified nurses and nursing-related outcomes such as medication errors, falls, and pressure ulcers. The researchers commented that their study was probably not sufficiently specific to critical care units to be able to establish significant correlations. Also, they were not able to determine the impact of certification on errors interceptions - an element that could be an important benefit for clinical care units. The following year, KendallGallagher, Aiken, Sloane and Cimiotti ${ }^{[57]}$ have shown, in the context of a retrospective correlational study, that the mortality rate and risk of complications were favorably influenced by the proportion of certified nurses. The authors were able to affirm that there is, indeed, a positive link between certification and patient outcomes. Donahue Piazza, Griffin, Dykes and Fitzpatrick ${ }^{[58]}$ were also able to demonstrate, through a correlational quantitative study conducted among 259 nurses and 1,606 patients of a northeastern U.S. hospital, that there is a "significant positive relationship between the perception of empowerment of nurses and patient satisfaction” level. Consequently, the authors asserted that it is important for health care institutions to promote the empowerment of their professionals. Finally, Spence Laschinger ${ }^{[20]}$ asserted that work environments that permit nurses to participate in decision making and allow better control over their clinical practice through, for example, certification, create a form of empowerment. Being better prepared, nurses are more likely to provide quality care directly optimizing patient satisfaction ${ }^{[59]}$. 


\section{Barriers to certification}

However, many barriers to the certification process are present in clinical care settings ${ }^{[55]}$. Lack of time and lack of perceived benefits for practice, as well as fear of failing the exam, are the barriers that are more often reported ${ }^{[43]}$. Costs associated with the certification process, the short time allowed to study, and lack of support from organizations have also been identified as barriers ${ }^{[52]}$. Although some nurses appear to experience a form of personal and professional development through the certification process, more efforts have to be deployed in clinical settings to support professionals who would like to engage in the certification process. It would potentially increase the number of certified professionals. In a survey conducted during a conference of the American Board of Nursing Specialties (ABNS) by Stromborg, Niebuhr, Prevost, Fabrey, Muenzen, Spence, Towers and Valentine ${ }^{[60]}$, it was found that $25 \%$ of organizations do not provide any form of support to nurses engaged in the certification process. According to researchers, this lack of encouragement can not only decrease the perception of psychological empowerment of nurses, but also affect the potential for success in the certification exam.

\section{The importance of organizational support}

CNA ${ }^{[41]}$, which develops and administers the Canadian nursing certification, provides nurses with information and organizational resources, such as mentoring, to support the certification process. In addition, some hospitals that recognize the benefits of certification process in terms of attraction and retention of nursing staffs, attempt, through various methods, to encourage nurses to engage in this process ${ }^{[61]}$. In the US, the AACN states that the certification process, although primarily based on the willingness of nurses to invest in self-learning, requires the presence of support and motivation in clinical care settings to encourage nurses to persevere and acquire new specialized knowledge ${ }^{\text {[29, } 62]}$. According to Tigert ${ }^{[9]}$, managers must implement measures providing information, resources, support, and opportunities to generate an environment conducive to personal and professional development. This author considers that allowing nurses to practice according to the highest standards of care increases job satisfaction and reduces stress. Similarly, Fitzpatrick et al. ${ }^{[18]}$ highlighted, following the analysis of a survey done with 6,589 nurses who are members of the AACN, that education and certification make a difference in the empowerment of nurses. Therefore, it is of utmost importance to promote advanced training and recognize clinical competency in order to retain the most efficient nurses in hospitals. Incentives encouraging nurses to get involved in the certification process may consist of scholarships, recognition in the organization, support groups, and career advancement opportunities ${ }^{[55]}$. By analyzing the results of a survey conducted with 11,427 nurses by the American Board of Nursing Specialties (ABNS) ${ }^{[63]}$ in 2006, these authors showed that nurses who feel supported by their employer have a sense of belonging. Finally, Nierbuhr \& Biel ${ }^{[55]}$ concluded that the certification process, when supported by the organizations and nursing associations, influences personal and professional satisfaction.

\section{Recommendations}

In order to help nurses prepare for national certification, several methods are proposed. Karvonen, Sayre and Wyant ${ }^{[62]}$ showed how two nurses, one specialized in staff development and a clinical nurse specialist, created, from the American nursing certification guide, a preparatory course to help medical-surgical nurses prepare for the exam. They divided the course into several sessions and provided theoretical and practical content, such as exercises, to facilitate learning. Participating nurses were also able to make in-depth links and sustain their motivation. The facilitators were not just teaching, but rather, they were mentoring and accompanying nurses throughout the learning period. Finally, the participants reported that this method has increased their level of expertise and success rate, and has promoted the strengthening of relationships among the professionals involved. Similar results were obtained with a comparable intervention with Canadian nurses undergoing certification in rehabilitation ${ }^{[64]}$. In 2005, Shirey ${ }^{[59]}$ reported how a hospital in Indiana increased the number of certified nurses in critical care from 4 to 34 in four years. According to this author, a comprehensive program must be implemented in an organization to encourage nurses to engage in the certification process. Scholarships, mobilization of clinical resources to answer questions during the study process, as well as recognition by the employer, can increase the number of participants. Patry ${ }^{[29]}$ explored, using a consultation process as 
part of a final graduate studies project in nursing at the University of Ottawa, the experience of nurses who participated in a study group to support their certification process. It was found that this method allowed the creation of strong links among participants who used this strategy to support their certification process. The 58 nurses who participated in the consultation were unanimous on the usefulness of the study group as a source of support and personal development. The only requirement for this method to be successful is the provision of financial and logistical support from the organization. In summary, many clinical settings have begun to implement supporting structures for professionals who undergo the certification process in a specialty. The process, therefore, deserves to be tested in different clinical care settings.

\section{Discussion}

This literature supposes that the certification process is considered by nurses to be beneficial on three levels: personal fulfillment, peer recognition, and professional credibility. Although a very small number of researches directly linked positive effects of empowerment generated by national certification on mental health, it remains that nurses from different specialties have identified several personal benefits, such as, feeling of self-accomplishment and increase in job satisfaction. Certification, according to literature, can improve autonomy, self-confidence, and a sense of clinical competence ${ }^{[28,53-55]}$. By generating satisfaction and growth (both personal and professional), positive effects on burnout, emergence of PTSD, and retention of human resources in intensive care units have been reported. For the organization, the national certification of professionals, by its positive effects on the mental health of the employees, was correlated with an increase in attractiveness and competitiveness of their institution. It is however appropriate that research continues in this area.

The key element emerging from the literature is the importance of the presence of support methods in health care settings. As mentioned by Kanter ${ }^{[45]}$ and Spence Laschinger ${ }^{[23]}$, organizational structures are the basis for the development of psychological empowerment. By establishing programs to support certification, organizations allow nurses to have maximum access to various resources. On one hand, in promoting this process, professionals note the presence of opportunities in their work environment. When organizations mobilize resources and facilitate access to clinical information to support studying, nurses understand that they are supported and encouraged in the certification process. By using various methods, such as the creation of study groups, clinical care settings allow nurses to relate to each other. On the other hand, by promoting recognition and involvement of certified professionals in the organization, the other employees recognize opportunities for advancement and the impact that certification entails.

The theoretical framework of Kanter ${ }^{[45]}$ reviewed by Spence Laschinger ${ }^{[23]}$ has established, using a clear structure, the components of empowerment, certification, and mental health identified in the literature. Although no researcher has looked at these three concepts in one study, as identified by the literature review, the theoretical framework has been a guide in establishing the direct and indirect impacts of the certification process on the health of nurses. Although the link between mental health and this process is still poorly documented, it is pertinent to explore the experience of nurses who have undergone the certification process. Niebuhr and Biel ${ }^{[55]}$ suggested that research should be conducted to identify what environmental elements contribute to enhance empowerment during the certification process. In fact, all the articles and documents (opinions and self-reports) consulted used non-experimental study designs, and therefore, no direct causal links can clearly be established. Multiple factors or combination of factors could have influenced results and the conclusion mentioned in these studies. Authors affirm that the certification process in a specialty area such as critical care contribute to psychological health and growth (personal and professional) of nurses. However, they also acknowledge the lack of strong evidence.

There is also a lack of knowledge on the psychological and professional impact of failing the certification process or having to retake the exam. Based on the review of many studies regarding the experience by nurses who have passed their certification, it was noted that a bias might be present in the nurses' responses. One study used a survey to gather information that has limitations ${ }^{[9,18,65]}$. Thus, nurses with greater interest and a more positive perception of the certification 
process may have been more likely to respond to the questionnaires. Future research should use validated tools and performance audits in order to obtain more objective data.

Better quality studies, with experimental and longitudinal designs, are strongly recommended to evaluate the causality between certification and psychological health improvement (satisfaction, well-being). Correlational and retrospective reviews retrieved for this literature review had some limits. Bias existed in analyzing participants' responses to questionnaires, the methodology used, and interpretation of results. Furthermore, results were often based on individual experiences or perceptions and were not supported by statistical analysis. Research should attempt to compare non-certified nurses to certified nurses in terms of performance. Differences on specific indicators, such as errors, incidents, and accidents reports, should be analyzed according to these two groups. Also, no studies evaluating nurses' growth and development following a successful certification process were found in the literature review. Research is needed to provide quantitative and objective benefits achieved by the certification process in critical care. Further research is needed to investigate, in depth, the correlation between certification, empowerment, and mental health of nurses to provide decision makers and managers with more evidence in order to invest in the certification process.

Finally, the authors of this review could have conducted a quality review of the articles selected to ensure a more thorough analysis, thus optimizing its impacts. However, the educational context in which this review was conducted was limited. In addition, the inclusion and exclusion criteria used to select articles could have been more refined in order to select articles directly linking the concepts of certification and empowerment. In fact, some articles selected were referring indirectly to the variables and thus should have been excluded. However, the authors wanted to perform a broader literature review to study the variables in depth.

\section{Conclusion}

National certification is a learning process that allows participants to enrich their knowledge in a specialty, acquire self-confidence, and develop a higher level of professional competence. However, this process remains an unexplored avenue in Canada and especially in Quebec. Nevertheless, the importance of the certification process in the nursing profession is beginning to be recognized at a political level ${ }^{[2]}$. Thus, this justifies that research has to be conducted to explore, in more depth, the contribution of the certification process for both organizations and professionals. In light of the literature review, Quebec's clinical care environments have everything to gain by investing in the promotion of the certification process. This option has proven its potential to improve the health of nurses, quality of care, and achievement of organizational goals. Nurses are professionals who, too often, neglect their own health in favor of that of their patients. It is time that organizations care about their professionals and get involved in their welfare in order to foster healthy, stimulating, and efficient work environments.

\section{References}

[1] Coomber, B., \& Louise Barriball, K. Impact of job satisfaction components on intent to leave and turnover for hospital-based nurses: A review of the research literature. International Journal of Nursing Studies. 2007; 44(2): 297-314. http://dx.doi.org/10.1016/j.ijnurstu.2006.02.004

[2] Desrosiers, G. L'évolution des soins infirmiers exige la création de spécialités infirmières. Perspectives infirmières. 2005(November/Deacmber): 6-7.

[3] Health Care Innovation Working Group. From innovation to action: The first report of the Health Care Innovation Working Group. 2012. Retrieved at http://www.councilofthefederation.ca/pdfs/Health\%20Innovation\%20Report-E-WEB.pdf

[4] Fletcher, M. Nursing by the numbers. Canadian Nurse. 2002; 98(8): 14-16.

[5] Kérouac, S. \& Salette, H. La formation universitaire des infirmières et infirmiers ; Une réponse aux défis des systèmes de santé. Mémoire publié par la SIDIIEF, Québec, Canada. Retrieved at http://www.sidiief.org/ /media/Files/7_0_Publications/7_1_PublicationsSIDIIEF/7_1_1_Profil_Formation/MemoireFCoule urInteractive.ashx. 2011. 
[6] Kuokkanen, L., Leino-Kilpi, H. \& Katajisto, J. Nurse empowerment, job-related satisfaction, and organizational commitment. Journal of Nursing Care Quality. 2003; 18(3): 184-192. PMid:12856902http://dx.doi.org/10.1097/00001786-200307000-00004

[7] Ministère de la Santé et des Services Sociaux du Québec. Plan stratégique 2010-2015 du ministère de la santé et des services sociaux. Québec, Canada: La Direction des communications du ministère de la Santé et des Services sociaux du Québec. 2010. Retrieved at http://publications.msss.gouv.qc.ca/acrobat/f/documentation/2010/10-717-02.pdf.

[8] Purdy, N. M. Effects of work environments on nursing and patient outcomes. Monograph. University of Western Ontario, London: Ontario, 2011.

[9] Tigert, J. A., \& Spence Laschinger, H. K. Critical care nurses' perceptions of workplace empowerment, magnet hospital traits and mental health. Dynamics. 2004; 15(4): 19-23. PMid:15638354

[10] Azoulay, E. \& Herridge, M. Understanding ICU staff burnout: the show must go on. American journal of respiratory and critical care medicine. 2011; 184: 1099-1100. http://dx.doi.org/10.1164/rccm.201109-1638ED

[11] Burgess, L., Irvine, F., \& Wallymahmed, A. Personality, stress and coping in intensive care nurses: a descriptive exploratory study. British association of critical care nurses. 2010; 15(3): 129-140. PMid:20500651http://dx.doi.org/10.1111/j.1478-5153.2009.00384.x

[12] Cavalheiro, A. M., Junior, D. F. M., \& Lopes, A. C. Stress in nurses working in intensive care units. Revista Latino-Americana de Enfermagem, 2008; 16(1): 29-35. PMid:18392527http://dx.doi.org/10.1590/S0104-11692008000100005

[13] Epp, K. Burnout in critical care nurses: a literature reviews. Dynamics. 2012; 23(4): 25-31. PMid:23342935

[14] Martins, C. C. F., Santos, V. E. P., Tourinho, F. S. V., Dantas, C. N., Gurgel, P. K. F., \& Nunes de Lima, K. Y. Impacts of stress on nursing staff of an intensive care unit. Journal of Nursing UFPE / Revista de Enfermagem UFPE. 2012; 6(10): $2364-2370$.

[15] Mealer, M. L., Shelton, M., Berg, B., Rothbaum, B. \& Moss, M. Increased prevalence of post-traumatic stress disorder symptoms in critical care nurses. American journal of respiratory and critical care medicine. 2007; 175: 693-697. PMid:17185650http://dx.doi.org/10.1164/rccm.200606-735OC

[16] Poncet, M. C., Toullic, P., Papazian, L., Kentish-Barnes, N., Timsit, J-F., Pochard, F., Azoulay, E. Burnout syndrome in critical care nursing staff. American journal of respiratory and critical care medicine. 2007; 175; 698-704. http://dx.doi.org/10.1164/rccm.200606-806OC

[17] Statistics Canada. Health and well-being of nurses. 2007. Retrieved at http://www41.statcan.gc.ca/2007/2966/ceb2966_002-eng.htm

[18] Fitzpatrick, J. J., Campo, T. M., Graham, G., \& Lavandero, R. Certification, empowerment, and intent to leave current position and the profession among critical care nurses. American journal of critical care. 2010; 19: 218-226. http://dx.doi.org/10.4037/ajcc2010442

[19] Leblanc, S., \& Sylvain, H. Exploration des stratégies d’empowerment au travail d’infirmières d’une région isolée du Québec. L'infirmière clinicienne. 2011; 8(2): 26-37.

[20] Spence Laschinger, H. K. Effect of empowerment on professional practice environments, work satisfaction, and patient care quality. Journal of nursing care quality. 2008; 23(4): 322-330.

PMid:18431259http://dx.doi.org/10.1097/01.NCQ.0000318028.67910.6b

[21] Nedd, N. Perceptions of empowerment and intent to stay. Nursing economics. 2006; 24(1): 13-18. PMid:16583601

[22] Piazza, I. M., Donahue, M., Dykes, P. C., Griffin, M. Q., \& Fitzpatrick, J. Differences in the perceptions of empowerment among nationally certified and noncertified nurses. Journal of nursing administration. 2006; 36: 277-83. PMid:16705309http://dx.doi.org/10.1097/00005110-200605000-00021

[23] Spence Laschinger, H.K. Workplace empowerment: theoretical framework. 2001. Retrieved at http://publish.uwo.ca/ hkl/res_wep_framework.html

[24] Etchison, M. Registered nurse empowerment and retention correlations. Master's thesis. Ball State University, Indiana, United States. 2012

[25] Martin, T. A. Formal and informal power, access to work empowerment structures, and intent to stay. Unpublished paper, Ball University, Indiana, United-States. 2010.

[26] American association of critical nurses (AACN). AACN study links empowerment and job/career satisfaction to certification. AACN Bold Voices. 2010; 2: 6. Retrieved at http://www.nxtbook.com/nxtbooks/aacn/boldvoices_201005/index.php?startid=6

[27] Canadian Federation of Nurses Unions (CFNU). La main d'oeuvre infirmière. 2012; February: 1-8. Retrieved at http://www.fcsii.ca/sites/default/files/2012.backgrounder.nursing_workforce.fr_0.pdf

[28] Gaberson, K. B., Schroeter, K., Killen, A. R., \& Valentine, W. A. The perceived value of certification by certified perioperative nurses. Nursing Outlook. 2003; 51(6): 272-276. http://dx.doi.org/10.1016/j.outlook.2003.09.003

[29] Patry, L. A. Certification: Exploiter ses acquis. Infirmiere Canadienne. 2006; 7(2): 12-17.

[30] Curtis, J. R., \& Puntillo, K. Is there an epidemic of burnout and post-traumatic stress in critical care clinicians? American journal of respiratory and critical care medicine. 2007; 175(7): 634-636. PMid:17384323http://dx.doi.org/10.1164/rccm.200702-194ED 
[31] Wåhlin, I., Ek, A-C., \& Idvall, E. Staff empowerment in intensive care: Nurses’ and physicians’ lived experiences. Intensive and critical care nursing. 2010; 26: 262-269. http://dx.doi.org/10.1016/j.iccn.2010.06.005

[32] St-Pierre, L., Alderson, M., \& St-Jean, M. Le travail infirmier en unité de soins intensifs adultes vu sous l’angle de la psychodynamique du travail. L’infirmière clinicienne. 2010; 7(1): 9-23.

[33] Stayt, L. C. Death, empathy and self preservation: The emotional labour of caring for families of the critically ill in adult intensive care. Journal of Clinical Nursing. 2009; 18(9): 1267-1275. PMid:19413555http://dx.doi.org/10.1111/j.1365-2702.2008.02712.x

[34] Shields, M., \& Wilkins, K. Enquête nationale sur le travail et la santé du personnel infirmier de 2005: Résultats. Institut canadien d'information sur la santé. Ottawa, Canada. 2005. Retrieved at https://secure.cihi.ca/free_products/NHSRep06_FR.pdf

[35] Milliken, T. F., Clements, P. T., \& Tillman, H. J. The impact of stress management on nurse productivity and retention. Nursing Economics. 2007; 25(4): 203-211. PMid:17847655

[36] Spence Laschinger, H. K., \& Finegan, J. Empowering nurses for work engagement and health in hospital settings. Journal of nursing administration. 2005; 35(10): 439-449. PMid:16220057http://dx.doi.org/10.1097/00005110-200510000-00005

[37] Cho, J., Spence Laschinger, H. K., \& Wong, C. Workplace empowerment, work engagement and organizational commitment of new graduate nurses. Nursing leadership. 2006; 19(3): 43-60.

[38] Upenieks, V. V. The interrelationship of organizational characteristics of magnet hospitals, Nursing leadership, and nursing job satisfaction. The Health Care Manager. 2003; 22(2): 83-98.

[39] Ridge, R. Nursing certification as a workforce strategy. Nursing Management. 2008; 39(8): 50-52. PMid:18690153http://dx.doi.org/10.1097/01.NUMA.0000333725.80733.64

[40] Canadian Nurses Association (CNA). Certification program history. 2011. Retrieved at http://www.nurseone.ca/Default.aspx?portlet=StaticHtmlViewerPortlet\&stmd=False\&plang=1\&ptdi=582

[41] Canadian Nurses Association (CNA). What is certification? 2013. Retrieved at http://www.nurseone.ca/Default.aspx?portlet=StaticHtmlViewerPortlet\&stmd=False\&plang=1\&ptdi=523

[42] Briggs, L.A., Brown, H., Kesten, K., \& Heath, J. Certification: A benchmark for critical care nursing excellence. Critical Care Nurse. 2006; 26(6): 47-53. PMid:17123951

[43] American association of critical nurses (AACN). Safeguarding the patient and the profession: The value of critical care. American journal of critical care. 2003; 12(2): 154-164. PMid:12625174

[44] Wade, C. H. Perceived effects of specialty nurse certification: A review of the literature. AORN journal. 2009; 89(1): 183-192. PMid:19121422http://dx.doi.org/10.1016/j.aorn.2008.06.015

[45] Kanter, R. M. Men and women of the corporation. New York, NY: BasicBooks, 1993.

[46] Spence Laschinger, H. K., Finegan, J., \& Shamian, J. The impact of workplace empowerment, organizational trust on staff nurses' work satisfaction and organizational commitment. Health care management review. 2001a; 26(3): 7-23. http://dx.doi.org/10.1097/00004010-200107000-00002

[47] Spence Laschinger, H. K., Finegan, J., Shamian, J., \& Wilk, P. Impact of structural and psychological empowerment on job strain in nursing work settings: expanding Kanter’s model. Journal of nursing administration. 2001b; 31(5): 260-272. http://dx.doi.org/10.1097/00005110-200105000-00006

[48] Spence Laschinger, H. K., Leiter, M., Day, A., \& Gilin, D. Workplace empowerment, incivility, and burnout: Impact on staff nurse recruitment and retention outcomes. Journal of nursing management. 2009; 17(3): 302-311. PMid:19426367http://dx.doi.org/10.1111/j.1365-2834.2009.00999.x

[49] Wynd, C. A. Current factors contributing to professionalism in nursing. Journal of Professional Nursing. 2003; 19: 251-261. http://dx.doi.org/10.1016/S8755-7223(03)00104-2

[50] Samedy, K., Griffin, M. T. Q., Capitulo, K. L., \& Fitzpatrick, J. J. Perceptions of structural empowerment: Differences between nationally certified perinatal nurses and perinatal nurses who are not nationally certified. Journal of continuing education in nursing. 2012; 43(10): 463-466. http://dx.doi.org/10.3928/00220124-20120301-74

[51] Krapohl, G., Manojlovich, M., Redman, R., \& Zhang, L. Nursing speciality certification and nursing-sensitive patient outcomes in the intensive care unit. American Journal of Critical Care. 2010; 19(6): 490-499. http://dx.doi.org/10.4037/ajcc2010406

[52] Byrne, M., Valentine, W., \& Carter, S. The value of certification : A research journey. AORN Journal. 2004; 79: 825-35. http://dx.doi.org/10.1016/S0001-2092(06)60823-5

[53] Sechrist, K. R., Valentine, W., \& Berlin, L. E. Perceived value of certification among certified, noncertified, and administrative perioperative Nurses. Journal of Professional Nursing. 2006; 22(4): 242-247. http://dx.doi.org/10.1016/j.profnurs.2005.11.001

[54] Grief, C. L. The perceived value of BCEN certification. Journal of emergency nursing. 2007; 33(3): 214-216. http://dx.doi.org/10.1016/j.jen.2006.12.021

[55] Niebuhr, B., \& Biel, M. The value of speciality nursing certification. Nursing outlook. 2007; 55(4): 176-181. PMid:17678682http://dx.doi.org/10.1016/j.outlook.2007.02.002 
[56] Miller, P. A., \& Boyle, D. K. Nursing speciality certification; A measure of expertise. Nursing management. 2008; October: 10-16. http://dx.doi.org/10.1097/01.NUMA.0000338302.02631.5b

[57] Kendall-Gallagher, D., Aiken, L. H., Sloane, D. M., \& Cimiotti, J. P. Nurse specialty certification, inpatient mortality, and failure to rescue. Journal of nursing scholarship. 2011; 43(2): 188-194. http://dx.doi.org/10.1111/j.1547-5069.2011.01391.x

[58] Donahue, M. O., Piazza, I. M., Quinn, M., Dykes, P. C., \& Fitzpatnick, J. J. The relationship between nurses’ perceptions of empowerment and patient satisfaction. Applied Nursing Research. 2008; 21(1): 2-7. http://dx.doi.org/10.1016/j.apnr.2007.11.001

[59] Shirey, M. R. Celebrating certification in nursing forces of magnetism in action. Nursing administration quarterly. 2005; 29(3): 245-253. PMid:16056159http://dx.doi.org/10.1097/00006216-200507000-00009

[60] Stromborg, M. F., Niebuhr, B., Prevost, S., Fabrey, L., Muenzen, P., Spence, C., et al. Valentine, W. Specialty certification more than a title. Nursing Management. 2005; 36(5): 36-46. PMid:15879996http://dx.doi.org/10.1097/00006247-200505000-00012

[61] Canadian Nurses Association (CNA). Nurses Recognize Top Employers - News Release. 2010, May 12th. Retrieved at http://www.cna-aiic.ca/en/nurses-recognize-top-employers-2/

[62] Karvonen, C. A., Sayre, C., \& Wyant, S. E. Building a medical-surgical certification review course: A blueprint for success. Journal for nurses in staff development. 2004; 20(5): 213-218. PMid:15683200http://dx.doi.org/10.1097/00124645-200409000-00003

[63] American Board of Nursing Specialties (ABNS). Specialty Nursing Certification: Nurses’ perceptions, values and behaviors. 2006: 1-15. Retrieved at http://www.nursingcertification.org/pdf/executive_summary.pdf

[64] Leclerc, A., Holdway, K., Kettyle, D., Ball, A., \& Keith, L. Nurses’ perceptions of rehabilitation certification. Canadian nurse. 2004; 100(2): 22-25. PMid:15011493

[65] Bekemeier, B. Credentialing for public health nurses: Personally valued ... But not well recognized. Public health nursing. 2007; 24(5): 439-448. http://dx.doi.org/10.1111/j.1525-1446.2007.00654.x 